\title{
CUBA Y NOSOTROS
}

\section{Jorge Edwards}

\begin{abstract}
No parecía, en sus primeras etapas, que la Revolución Cubana seguiría los modelos de represión intelectual de los países del bloque soviético. Cuarenta años después, advierte Jorge Edwards, no hay duda de que a poco andar hubo signos inquietantes y preclaros del rumbo que iban a tomar las cosas en la isla. ¿Cómo fue que los intelectuales y escritores de afuera, los de las capitales de la lengua española, los de París, no lo percataran? ¿Por qué el entusiasmo con el castrismo fue tan persistente, prolongado y resistente al análisis? El escritor chileno rememora en estas páginas episodios de su contacto directo e indirecto con el régimen castrista entre los años 1958, comienzos de la Revolución, y 1974, cuando empieza a formarse, en torno a Octavio Paz y después a la revista Vuelta, un grupo de escritores, artistas e intelectuales iberoamericanos de tendencia liberal o socialdemócrata, en contraste con los sectores castristas y marxistas. La tajante división que devino en el mundo de la lengua española, como manifestación de la guerra fría, todavía sobrevive de alguna manera y sólo podrá terminar de verdad, a juicio de Edwards, cuando comience la transición cubana.
\end{abstract}

JoRGE EDwARDS. Escritor y ensayista. Miembro de la Academia Chilena de la Lengua, en 1994 recibió el Premio Nacional de Literatura y en 1999 el Premio Cervantes de Literatura. Autor de libros de cuentos y de las novelas El Peso de la Noche, Persona Non Grata, El Museo de Cera, Convidados de Piedra y El Origen del Mundo. Su novela más reciente es El Sueño de la Historia (Tusquets, 2000). 
$\mathrm{T}_{\mathrm{u}}$

uve las primeras noticias directas de la Revolución Cubana en la universidad norteamericana de Princeton, en el otoño de 1958, poco antes de la caída de la dictadura de Fulgencio Batista. La mansión en las afueras de la ciudad de un personaje que tenía conexiones familiares con Cuba se había convertido en lugar de encuentro de cubanos y latinoamericanos, punto más concurrido a medida que terminaba el año y se acercaba el momento en que los guerrilleros de la Sierra Maestra entrarían en La Habana. En esa casa lujosa, con aires del sur de los Estados Unidos, encontré a figuras conocidas de la resistencia civil contra el régimen de Batista, entre ellas al juez Manuel Urrutia, el primer y efímero Presidente de la República bajo el castrismo, y a jóvenes de sectores liberales que bajaban en sus automóviles hasta las costas de Florida y embarcaban armamento con destino a las huestes revolucionarias. Yo había salido a la calle en Chile pocos años antes para protestar contra la invasión de Guatemala por una fuerza militar apoyada por los Estados Unidos. Toda mi simpatía estaba con la oposición armada cubana a la dictadura. Me acuerdo de haber acompañado a uno de estos jóvenes cubanos, Felipe Pazos, a una discusión con sectores académicos y con empresarios de la comunidad princetoniana. Era todo un ejercicio de defensa moral e intelectual de la lucha contra Batista, y me parece que aporté más de algún argumento en aquella oportunidad.

En Princeton, en la misma casa de la que ya he hablado, vi las primeras imágenes del triunfo de Fidel Castro y de sus compañeros. Pocas semanas más tarde la televisión transmitió una escena de Fidel con su hijo, ambientada en lo que parecía el dormitorio de Fidelito, con ambos vestidos de pijama a rayas. Fidel pretendía transmitir una impresión de personaje informal, de familia, capaz de entrar con su palabra y hasta con sus gestos en el interior de los hogares de Estados Unidos. En los salones del personaje de Princeton, las imágenes de la pantalla provocaron reacciones divididas. Algunos entre los espectadores sonreían con simpatía, pero otros sentían que la actuación de Castro era demagógica y hasta grosera, de mal presagio para los días que vendrían.

En abril de 1959 el Comandante Castro fue invitado a los Estados Unidos por la Asociación Nacional de la Prensa. La relación de un grupo de gente de Princeton con el nuevo régimen de La Habana quedó en evidencia. Desde luego, la universidad aprovechó la ocasión para pedirle al Comandante en Jefe una charla en el Centro Woodrow Wilson de Asuntos Públicos e Internacionales, donde yo estudiaba un postgrado en mi condición de joven diplomático chileno. La charla, detalle interesante, iba a 
formar parte de un curso acerca de la Revolución Francesa que impartía un conocido especialista en el tema, el profesor Palmer. Y Fidel Castro se alojó en la casa bien provista de Roland Ely Taylor y de su esposa, el lugar que ya he mencionado como punto de encuentro cubano desde el año anterior. Supe detalles de la invitación de la universidad, que había destinado para el caso, en forma perfectamente deliberada, una sala muy estrecha, y que había repartido invitaciones seleccionadas a miembros de los sectores de historia y de ciencias políticas y sociales. La suspicacia por el lado norteamericano, en aquellos años de gobierno republicano del general Eisenhower y de vicepresidencia de Richard Nixon, era evidente, notoria, irritante para un joven que simpatizaba con la nueva Cuba. A todo esto, Fidel hacía un discurso de apaciguamiento, de seducción, de franca moderación, y tenía de su lado a buena parte de la opinión llamada liberal. Frente a los ciento y tantos invitados del Woodrow Wilson Center, con un inglés limitado, pero expresivo, trazó a grandes pinceladas el cuadro de una reforma agraria prudente, destinada a crear nuevos propietarios agrícolas, especie humana que se había conocido muy poco en la isla en épocas anteriores y que ahora, en los nuevos tiempos, formaría un excelente mercado para las exportaciones norteamericanas. A pesar de esto, el presidente Eisenhower no quiso recibir a Fidel a su paso por Washington y prefirió salir a jugar una partida de golf. A fines de marzo de 1971, cuando discutimos largamente antes de mi salida en la madrugada siguiente, al cabo de tres meses y medio de accidentada misión diplomática mía en La Habana, le cité sus palabras de Princeton, buen ejemplo de política conciliadora, y el Comandante negó con gran énfasis el hecho de haber estado nunca en el Woodrow Wilson Center. Después, ante la insistencia mía y la confirmación de Raúl Roa, entonces ministro de Relaciones Exteriores, reaccionó como niño sorprendido en falta (“iTú estabas allí!”), y la conversación adquirió un cariz bastante menos áspero.

De regreso en Chile, en octubre de 1959, tuve un nuevo contacto con la Revolución Cubana. Lo tuve en calidad de simple observador, pero colocado en un punto de observación francamente privilegiado. El jefe de Protocolo me llamó un día y me pidió, en mi calidad de persona "lectora y aficionada a la literatura", que fuera edecán de Raúl Porras Barrenechea, historiador, ensayista, Canciller del Perú y presidente de la delegación peruana a una reunión del sistema interamericano que tendría lugar en Santiago. Raúl Roa, el mismo Canciller a quien conocería más tarde en La Habana, presidía la delegación de Cuba. La Organización de Estados Americanos todavía estaba lejos de expulsar al régimen castrista, el que tampoco proclamaba todavía su adhesión decidida al bloque soviético, pero el 
debate interno era apasionado, de gran violencia verbal. Era un espectáculo que nunca se había visto en conferencias de esta clase. El canciller cubano y el de la República Dominicana, la del "Benefactor" Trujillo, la del "Chivo" de la última novela de Mario Vargas Llosa, estaban en lo que podríamos llamar la primera línea de las escaramuzas verbales. Eran intercambios violentos, llenos de acusaciones extremas y de fuego retórico. En medio de la conferencia llegó Raúl Castro a Santiago escoltado por un grupo numeroso de guerrilleros y guerrilleras en uniformes verde oliva. Me acuerdo bien de la actitud concentrada y cautelosa de Porras Barrenechea. Detestaba la dictadura de Trujillo, no detestaba menos al "imperialismo norteamericano" y tenía por los revolucionarios cubanos una simpatía notoria, aunque no declarada, quizás porque se encontraba rodeado de representantes de los segmentos más conservadores de la política del Perú. Fui testigo presencial de un detalle curioso. Uno de los miembros de su delegación, viejo diplomático y partidario incondicional del gobierno de Manuel Prado, abrió su maleta en su habitación del Hotel Carrera y encima de la ropa vimos un pesado crucifijo de madera y de marfil que lo acompañaba, por lo visto, en todos sus viajes.

En las tardes salíamos de la agitada sala de reuniones y el Ministro Porras, encantado con el clima suave de la primavera santiaguina, me pedía que lo acompañara a librerías de viejo. En esas ocasiones hablábamos de escritores peruanos, chilenos, latinoamericanos: de César Vallejo, de cuya edición póstuma de Poemas Humanos se había encargado en persona poco después de la muerte del poeta en París; de Pablo Neruda y Vicente Huidobro; de Jorge Luis Borges. Él se interesaba en la poesía de tono menor, de patios y callejuelas de arrabales, con lejanos ecos de tangos y de milongas, de Fervor de Buenos Aires, pero observaba con sorpresa que los jóvenes escritores de Lima leían las mismas cosas que yo le comentaba y que leían mis amigos de Santiago: el Borges de El Aleph, de Otras Inquisiciones, de Historia Universal de la Infamia. No estaba de acuerdo con nuestro gusto, pero la coincidencia le parecía interesante. Me anunció una invitación al Perú para presentarme a los jóvenes autores de allá. El Ministro hizo poco tiempo más tarde, en otra reunión de la OEA, la encendida defensa del principio de no intervención, que habría permitido coexistir en América del Norte y del Sur con el régimen de Castro, y murió de un ataque cardíaco provocado, según se dijo, por este esfuerzo. Un par de años después me encontré en París, en un programa en español de la Radio Francesa, con uno de los jóvenes que leían al Jorge Luis Borges "difícil" y que a la vez habían sido discípulos del Ministro historiador y hombre de letras, Mario Vargas Llosa. 
Ahora pienso que mis primeros encuentros con Vargas Llosa, a partir de junio o julio de 1962, estuvieron marcados por la atmósfera optimista, generosa, juvenil, de los comienzos de la Revolución Cubana. Todavía veo al joven peruano, cuya primera novela, La Ciudad y los Perros, aún estaba inédita, en la tribuna de la Mutualité, en París, al lado de JeanPaul Sartre, de Simone de Beauvoir, de algún otro que ahora no recuerdo. Vargas Llosa decía en tonos apasionados, con un francés impecable, que los grandes responsables del atraso, de la miseria, de la injusticia en su país eran una trinidad formada por el Ejército, la Iglesia y la Oligarquía. El Mario de aquellos días vivía en un pequeño y desvencijado departamento de la rue de Tournon. Trabajaba de noche en la Radio Francesa y escribía a partir del mediodía como un forzado hasta más o menos las siete o las ocho de la noche. Frente a su mesa de trabajo tenía una edición de tapas rojizas, en rústica, de las obras completas de Lenin, detalle que nunca dejaba de asombrarse, pero en su conversación no aparecía nunca la literatura de Lenin, sino la de Gustave Flaubert, William Faulkner, Balzac, Tolstoi, Joan Martorell, el novelista medieval de Tirante el Blanco. Después de entregarle el manuscrito de La Ciudad y los Perros a Carlos Barral, a quien me parece que había conocido a través de Claude Couffon, había entrado ya en el tema de La Casa Verde. Escribía como novelista del siglo XIX, rodeado de mapas de los lugares y de hojas con la cronología y los personajes de su historia pegadas con chinches en las paredes. La naciente revolución cubana acaparaba las conversaciones de café, las del Old Navy o La Coupole, para citar un par de lugares emblemáticos, pero Mario, precisamente, rehuía por principio aquellos encuentros nocturnos. Después de la jornada literaria suya y de la mía en la diplomacia chilena, solíamos reunirnos para ir a ver un "western", su género preferido en el cine. Y en los fines de semana visitábamos casas o lugares de escritores, compartiendo en estas excursiones los gustos de cada cual de una manera pacífica: un fin de semana el Rouen y el Croisset de Gustave Flaubert; otro, el Illiers de Marcel Proust. Cada excursión era una historia inesperada y divertida, llena de incidentes curiosos. Cada una podría formar el capítulo de un libro. El hospital, el pabellón de Croisset, la plaza de Rouen, fueron mi iniciación en el mundo flaubertiano, así como la visita de Illiers terminó por llevar a Mario, reticente hasta entonces, a la lectura de Proust.

A mí me parece hoy, con nada menos que cuarenta años de perspectiva, que la libertad de creación literaria era una de las preocupaciones centrales del joven Vargas Llosa, una opción que estaba destinada a alejarlo del socialismo real en cualquiera de sus formas. Parecía en las primeras etapas que la Revolución Cubana no seguiría los modelos de represión intelectual de los países del bloque soviético. Las revistas isleñas mostra- 
ban una fascinación algo tardía, pero en cualquier caso interesante, por el surrealismo y por las vanguardias europeas, fenómeno que también se daba en las artes plásticas. A poco andar, sin embargo, en forma contradictoria, empezaron a manifestarse signos inquietantes. El fin prematuro del suplemento Lunes de Revolución, que coincidió con la prohibición de la película documental P. M. y con los primeros problemas de Guillermo Cabrera Infante y de Heberto Padilla, indicó en forma clara, para entendedores lúcidos, el rumbo que iban a tomar las cosas. En una célebre reunión con los intelectuales isleños, Fidel hizo una declaración que no todos comprendieron en su verdadero alcance: "Dentro de la Revolución, todo; contra la Revolución, nada". En aquella misma reunión, un escritor sólo conocido por una minoría, hombre de aspecto frágil, apocado, dijo en público lo siguiente: "Yo tengo mucho miedo". No dijo casi nada más, pero era más que suficiente. Mi impresión actual es que los intelectuales de afuera, los de las capitales de la lengua española, los de París, fuimos demasiado lentos para sacar las consecuencias de esta situación. El entusiasmo con el castrismo fue persistente, prolongado, resistente al análisis. La comparación de lo que pasaba en Cuba con lo que había pasado décadas antes en la Unión Soviética era decididamente mal vista. Cabrera Infante, uno de los primeros exiliados intelectuales, fue condenado y aislado por casi todos nosotros en los tiempos de su llegada a Londres, en forma explícita o tácita. Ahora, después de alrededor de cuarenta años, he comprobado que Virgilio Piñera, el que se atrevió a confesar su miedo en las barbas mismas del Comandante en Jefe, es el ídolo más sólido para los escritores jóvenes de Cuba, por lo menos para los que han conseguido escapar en años recientes. Una tarde, durante mi estada como diplomático del gobierno de Salvador Allende, fui a visitar a Pepe Rodríguez Feo en su departamento de La Habana. Después de la visita salimos a un corredor en penumbra y vimos a una sombra que se deslizaba y entraba en un pequeño departamento vecino. "Es Virgilio Piñera", susurró Rodríguez Feo. Pensé en los poetas, en la gente de verdadera imaginación creadora, reducidos a la condición de sombras, en curioso contraste con la luz caribeña. Pero fue sólo un instante y una rápida imagen: un ser que pasaba cerca, encorvado, y que se refugiaba en su cubículo, en su recinto secreto. Pues bien, me pareció interesante que los jóvenes escritores, después de más de treinta años, puedan amar y admirar a ese personaje de la penumbra más que a cualquier detentador de los poderes fácticos. Los aficionados a viajar y a retratarse junto al Comandante en Jefe, cualquiera que sea su ideología, deberían sacar a tiempo las conclusiones que correspondan. Yo habría preferido el descenso al Hades con este singular Virgilio de la Isla. 
Si el rechazo de toda censura fue una de las obsesiones del joven Vargas Llosa, creo que hubo otro factor poderoso que contribuyó a alejarlo del socialismo real. Después del rápido éxito internacional de La Ciudad y los Perros, el nuevo novelista peruano se puso en la mira de muchos cenáculos literarios de América Latina. Fue víctima de la envidia de aquel personaje que él mismo definió como "intelectual barato". Hay que haber vivido en aquellos años para entender los extremos a los que se podía llegar. La ideología se transformaba con facilidad en maquinaria de acusaciones y delaciones interminables, en las que cada cual trataba de colocarse a la izquierda del otro. Fueron pocos los escritores y artistas de aquella época que no conocieron esta espiral de la delación. Nicanor Parra recibió andanadas furiosas por haberse permitido tomar una taza de té con la señora del presidente Richard Nixon. Pablo Neruda fue acusado en una carta pública de los intelectuales cubanos, firmada con rara unanimidad, de haberse "aburguesado" y de haber pactado con el enemigo político por el solo hecho de haber viajado a una reunión del Pen Club Internacional en Nueva York y de haber aceptado una condecoración del gobierno peruano que presidía entonces Fernando Belaúnde.

No eran tiempos fáciles. Eran años de inquisiciones, de tribunales del pueblo, de comisarios autodesignados. Decir otra cosa hoy sería embellecer y falsear nuestro pasado más o menos reciente. El último entusiasmo castrista de Mario Vargas Llosa que recuerdo es el de las crónicas que envió desde La Habana durante la crisis de octubre de 1962. "Nikita, Nikita, lo que se da no se quita", cantaba el pueblo cubano en las rampas habaneras, poco después del retiro de los misiles convenido entre John Kennedy y Nikita Kruschev, y las crónicas de Vargas Llosa, publicadas si no recuerdo mal en Le Monde, transmitían esta reacción espontánea con toda su rabia y toda su espontánea frescura. Poco tiempo más tarde invité a Mario y a su mujer de entonces, Julia Urquidi, a una representación del "Galileo Galilei" de Bertolt Brecht por el Teatro Nacional Popular de Francia. Aparecieron en compañía de una señora mayor, delgada, de aspecto algo enfermizo, de acento marcadamente argentino. Se hospedaba en el departamento de la rue de Tournon y había llegado con recomendaciones de una peruana residente en Cuba. Después supe por Mario que la peruana era Hilda Gadea, primera mujer del Che Guevara, y que la señora de acento argentino era nada menos que la mamá del Che. No recuerdo detalles precisos, pero puedo asegurar que la señora hablaba de la situación cubana sin euforia, con reservas no enteramente explícitas, como si diera a entender que se había producido una deriva o una burocratización no deseables. A nosotros nos asombró, por otro lado, que la madre de un gran personaje 
político de América Latina no se alojara en un hotel de cinco estrellas sino en la modesta residencia de un joven escritor. Era un motivo para confirmar nuestra fe política, a pesar de la reticencia un tanto oscura con que se expresaba la mamá del Che.

La carta contra Neruda fue seguida de cerca por otro episodio desagradable, que afectó esta vez en forma directa y personal a Vargas Llosa. Frente al hecho seguro de que la segunda de sus novelas, La Casa Verde, obtendría el premio venezolano Rómulo Gallegos, la embajada de Cuba en Londres y Alejo Carpentier en persona le habían propuesto que entregara públicamente el dinero a la guerrilla del Che Guevara, con la seguridad de que esta suma le sería reintegrada en mensualidades por la embajada. Vargas Llosa rechazó de plano este arreglo y todo el asunto salió a la luz con motivo de la entrega del premio. Era un conflicto abierto, declarado, que ya no se podía disimular. Uno de los primeros llamados de apoyo que recibió el novelista fue el que le hizo desde Santiago de Chile a Caracas Pablo Neruda. Era el germen de una disidencia y de una crítica de los métodos del castrismo que se incubaba en el interior mismo de la izquierda latinoamericana. De hecho, la carta contra Neruda y el episodio del Rómulo Gallegos señalaron el principio de una evolución que ya no tendría vuelta. En esos días se produjo otra crisis en el sector intelectual con motivo del premio de Casa de las Américas otorgado por un jurado internacional y, desde luego, con gran molestia de las autoridades, a Fuera de Juego, colección de poemas de Heberto Padilla. Era, como lo indicaba su título, un libro de repliegue, de escepticismo, de distancia con respecto al fervor revolucionario. Fue publicado con un prólogo crítico de Nicolás Guillén, donde se daba curso a todas las reservas oficiales, y fue objeto de los virulentos ataques de la revista Verde Olivo, editada por las Fuerzas Armadas. Ahí comenzaba un episodio decisivo en la relación del poder castrista con lo intelectual del interior y de afuera: el caso Padilla.

Mi último encuentro con Mario Vargas Llosa en Cuba tuvo lugar a fines del año 70 o en los comienzos de 1971. Hubo, por iniciativa mía, entonces Encargado de Negocios de Chile, cosa que los servicios secretos habrán anotado como grave antecedente en mi contra, un almuerzo memorable en compañía de Mario y de José Lezama Lima. Lezama nos habló con visible miedo, detalle que a mí ya no me sorprendía, pero que Mario recuerda con asombro hasta el día de hoy, de la situación interna, del soplonaje, del absoluto control de la vida literaria, del desastroso estado de la economía. De repente señaló el florero que servía de centro de mesa en el restaurante, sugiriendo que ahí podían esconderse los ineludibles micrófonos. Cuando nos separamos de Lezama Lima, Mario estaba horrorizado, 
angustiado. Lo curioso es que Julio Cortázar también visitaba la isla en esos días y parecía flotar en el mejor de los mundos revolucionarios posibles. Cada vez que se acercaba a un grupo donde se desarrollaba una conversación difícil, donde se hablaba del "temita", para emplear una expresión habitual, la gente, justamente, cambiaba de tema en forma inmediata.

Heberto Padilla fue encarcelado un día viernes en la noche, después de haberme visitado en mis habitaciones del hotel Habana Riviera junto con Saverio Tutino, corresponsal hasta hacía poco de L'Unitá en La Habana, y con José Norberto Fuentes, autor entonces de Condenados de Condado y que tuvo que abandonar la isla años después a causa, en parte, de su amistad con el general caído en desgracia y fusilado Arnaldo Ochoa y con los hermanos La Guardia. Salí de Cuba en la madrugada de ese lunes, ya destinado para trabajar como ministro consejero en la embajada chilena en Francia, encabezada por Pablo Neruda, y sin saber cuál sería el destino de Heberto Padilla. En alguna forma, el caso Padilla era el caso mío. Había conversado largo con Fidel Castro en la noche del domingo, pocas horas antes de tomar el avión de Iberia a Madrid, y el Comandante me había insinuado que Padilla tenía "ciertas" ambiciones políticas, cosa que no me pareció nada de convincente entonces y que todavía no me convence. Por lo demás, no me parece que tener ambiciones políticas sea delito en ninguna parte. Alojé una o dos noches en la casa de Mario en Barcelona y le conté todo el episodio del encarcelamiento de Padilla y de mis pasos finales en la isla, incluyendo la conversación de cuatro horas con Fidel Castro, sin omitir detalle. Después llegué a París y le conté la misma historia a Pablo Neruda, mi flamante jefe de misión. Tuve la impresión de que entendía mejor que nadie lo que me había ocurrido, de que mi relato confirmaba suposiciones y hasta experiencias y conocimientos suyos acerca del socialismo real, pero de que a la vez olfateaba, con su nariz fina, una situación altamente peligrosa en esos días iniciales del gobierno de la Unidad Popular. Sentía una especial irritación frente a la revista Libre, dirigida entonces en París por Juan Goytisolo y Plinio Apuleyo Mendoza, y me insistió mucho para que no colaborara con ellos. También me transmitió un consejo, supongo que recibido por carta, de Volodia Teitelboim: que no firmara ninguna de las protestas por el caso Padilla, que no abriera la boca. La verdad es que me bastaba con seguir las instrucciones generales al cuerpo diplomático: el rápido "consejo" de Volodia era perfectamente innecesario. Un día me visitó en mi oficina José Agustín Goytisolo y después, al salir, nos encontramos a boca de jarro con Neruda y con el embajador de Cuba. Fue un momento de confusión, pero los gestos exagerados y horrorizados 
de José Agustín le dieron un toque irresistiblemente cómico. Neruda me contó después que el embajador cubano, Baudilio Castellanos, conocido por sus numerosos amigos como Bilito, le había hecho notar que en la embajada chilena faltaba vigilancia. Neruda me dijo que le contestó, con todas sus letras, que a él no le gustaba el "policial socialismo".

Guardé silencio, pues, en medio de la agitación de mis amigos escritores, y el caso Padilla se hizo célebre en todas partes y siguió el curso que todos conocen. A fines de diciembre de 1973 se publicó en Barral Editores mi testimonio personal, escrito en las madrugadas de 1971, antes de partir a mis oficinas de la avenida de la Motte-Picquet, y completado con un epílogo después del golpe militar del 11 de septiembre y cuando yo había sido borrado de las filas de la diplomacia chilena. Las reacciones editoriales fueron sorprendentes y reveladoras. Una conocida firma alemana pidió por telegrama que no le mandaran el libro en lectura porque "ya sabían de qué se trataba". Otra editorial de la misma lengua dijo que no podía publicarlo, pero pidió permiso para no devolver el ejemplar de lectura porque su lector se había entusiasmado con la obra y quería conservarla. Podría escribir un pequeño ensayo llamado "Misterios editoriales" y quizás lo haga algún día.

A comienzos de 1974 pasaron por Barcelona Mari Jo y Octavio Paz y fueron una tarde a la casa de Carlos Barral en la calle Ganduxer. Carlos me llamó por teléfono para decirme que Octavio Paz quería conocerme. Me agregó que también habían llegado a su casa los Vargas Llosa. Fuimos a cenar a un restaurante cercano y Octavio me dijo que Persona Non Grata le parecía un libro importante, pero que nadie en México se atrevía a escribir sobre él. Ahí mismo, cuando ya estábamos sentados a la mesa, le pidió a Mario Vargas Llosa que escribiera sobre el libro para la revista Plural, que él dirigía entonces. Poco después apareció un número de Plural con el texto de Mario, "Un francotirador tranquilo", y con otro del gran crítico uruguayo Emir Rodríguez Monegal. Ya se formaba en torno a Octavio Paz y a la revista que fundaría muy pronto, Vuelta, un grupo de escritores, artistas e intelectuales iberoamericanos cuya tendencia se podría definir como liberal o socialdemócrata, en contraste con los sectores castristas o marxistas donde se alineaban Julio Cortázar, Gabriel García Márquez o Mario Benedetti. Era una división tajante en el mundo de nuestra lengua: una manifestación particular, de caracteres bien acusados, de la Guerra Fría. Aquella división perdió gran parte de su sentido con el desplome del bloque soviético, pero todavía sobrevive de alguna manera. Sólo podrá terminar de verdad y verse como cosa del pasado cuando comience la transición cubana, fenómeno político e histórico que ya no está demasiado lejos de nosotros. 